\title{
Prevalence of Stroke in Kingdom of Saudi Arabia - Through a Physiotherapist Diary
}

\author{
Khalid Alahmari \\ Dean, College of Applied Sciences, King Khalid University, Abha, Kingdom of Saudi Arabia \\ Email:kahmarie@kku.edu.sa
}

Paul S. S

Assistant Professor, College of Applied Sciences, King Khalid University, Abha, Kingdom of Saudi Arabia Email: paulsilvian@kku.edu.sa; *corresponding author

\section{Doi:10.5901/mjss.2016.v7n1s1p228}

\begin{abstract}
In Saudi Arabia, according to statistics, cardiovascular disease amounts to a major cause of deaths each year. Current data on stroke in the Kingdom of Saudi Arabia are lacking. This study is a national survey to inform decision-makers on the current magnitude of the epidemic. The data obtained for this study is from the nationwide physiotherapy departments that provide rehabilitative treatments to stroke patients. The study also tries to systematically analyze the published prevalence of many international countries and have tried to compare it with the available data of stroke prevalence in Saudi Arabia. The results shown in this study do make us understand that it is still not late to bring in preventive actions against stroke in Saudi Arabia.
\end{abstract}

Keywords: stroke, prevalence, saudi arabia

\section{Introduction}

"Health care is an increasing concern" is the usual paragraph starter of any health related journal paper written in GCC country. Be that the McKinsey report by Mourshed et al., 2010, or Algazy, 2009 or Klautzer et al., 2014, each of these papers constantly remind about the health care problems to be envisaged in Gulf Countries. It may seem biased to call a Country to be "very high in coronary heart diseases" (Klautzer et al., 2014), and for researchers to predict that GCC will have an exponential growth in the number of lifestyle diseases in the coming future. This paper would rely heavily on the McKinsey report that projects treatment demand in GCC by 2025. Over the next 20 years, treatment demand will rise in the GCC by 240 percent. It is also expected that in particular, cardiovascular disease will experience a steep increase (419 percent), as will diabetes-related ailments (323 percent). But most of these projections are made generic, for example, cardio vascular, infectious disease, maternal and perinatal disease, and digestive and genitourinary diseases etc. Keeping this statistics in mind this research is an attempt to find out the total cases of Stroke patients in Kingdom of Saudi Arabia, one that would help in deep probing of the problem at hand.

The Kingdom of Saudi Arabia (KSA) is the largest country in the Middle East. It occupies approximately four-fifths of the Arabian Peninsula constituting a population of more than 28 million. In Saudi Arabia, according to statistics, cardiovascular disease amounts for 22 percent of deaths each year (Ashirwatham and Zamzam, 2014). Current data on stroke in the Kingdom of Saudi Arabia are lacking. We conducted a national survey to inform decision-makers on the current magnitude of the epidemic. Stroke, otherwise called hemiplegia is caused due to blood clots or embolus which travels in the systemic circulation suddenly blocks the arteries of the brain leading to paralysis of the opposite side of the body being supplied by the brain, if the right side of the brain is affected, the left side of the body becomes paralyzed and vice versa, it is a cerebrovascular accident ultimately due to ischemic changes or lack of blood flow. Stroke is increasingly emerging as a major health problem, in Middle East region (Tran et al., 2010). In a study by Kamran et al., 2007 reported that a major percentage of the patients had not even heard the term "stroke" in the Gulf Cooperation Council (GCC) countries. The study made an alarming find that the knowledge regarding stroke was poorest among the groups that belonged to the highest risk bracket for stroke, as per the study. Studies have looked into the cause factors of stroke in Middle East region and have attributed old age, high blood pressure, prior stroke or Transient Ischemic Attack (TIA), diabetes, high cholesterol, tobacco smoking and atrial fibrillation as the major risk factors for stroke (Robert and Zamzami, 2014). Studies have proved that a person with diabetes, blood pressure, or high cholesterol is more at risk for a stroke (Awada and Al Rajeh, 1999). A lot of factors that increase the risk of a stroke includes obesity, smoking, 
sedentary lifestyle, etc. Even gender differences of stroke in Saudi Arabia are studied and research indicates that prevalence of stroke among men than women (Yaqub et al., 1991).

Stroke can leave an individual with a residual damage of physical, psychological, social and cognitive functions, depending on tand severity of the epidemic. In another study by Al Kathaami et al., 2011 who interviewed neurologists about their views on stroke, reports that acute stroke care in Saudi Arabia as inadequate. Al Rajeh et al., 1993, who studied about 500 consecutive patients with first-ever stroke admitted in a hospital that exclusively serves the Saudi Arabian National Guard community suggested that stroke incidence is low in Saudi Arabia compared with industrialized countries. They presume that it would be because of the predominance of young age groups in the country. Their study held that overall distribution of stroke types was closer to that of Western populations than to the Japanese, in whom hemorrhagic strokes were highly prevalent at that time. Ever since 1993 there has been an increase in the number of stroke patients in Saudi Arabia. Akbar et al., (2001) showed that stroke was more frequent in the sixth decade of life with male predominance in both Saudis and non-Saudis, a finding similar to what has been reported by others (Al Jishi and Mohan 1999, Awada and Al Rajeh, 1999). This might be a reason to start a nationwide survey on the prevalence of the epidemic.

Research has shown that the Middle East region faces a double burden of the disease due to decreasing rates of communicable diseases and the growing rates of non-communicable diseases (Robert and Zamzami, 2014; Akala and El- Saharty, 2006). Quari (2000) conducted a study among stroke patients who were admitted at King Abdul Aziz University Hospital and found that there was a high incidence of thrombotic stroke in their study. In 2012 a study was conducted by Al Aqueel et al., who reported an alarming deficit in the level of stroke awareness in the Saudi population. Urgent public health measures to correct this deficiency, which will match the rate of similar countries, was also suggested to be implied.

The overall literature survey points that there is a dearth of stroke data in physiotherapy departments and rehabilitation centres in Saudi Arabia. Research studies available on stroke cases in physiotherapy deals with trials, experiments and interventions. One study has looked into the characteristics which are most associated with free-living and lack of physical activity in community-dwelling ambulatory people after stroke, but the respondent size was too low i.e, 18 cases (Alzharani et al., 2011). Such studies would not be able to bring about the real size of stroke epidemic in the country.

Review of published literature available on stroke in Middle East region points out that they are either projections or is specific to particular regions of Saudi Arabia. This paper is one of a kind in itself that we have conducted a national level survey in order to find out the prevalence of Stroke cases in the whole Kingdom from a physiotherapist perspective. The data has the number of stroke cases present in physiotherapy departments in each of the region of the Kingdom. Such a data can help the policy makers to take actions to start organising nation-wide stroke care and to further up on the existing evidence-practice gap as reported by many researchers. The lack of stroke related research especially in physiotherapy makes this paper unique. The objective of this study is to provide primafacea information about stroke prevalence, since all the cases are referred post stroke attack.

\section{Literature Review}

Table 1: List of available Literature in the Kingdom:

\begin{tabular}{|l|l|l|l|}
\hline Researchers & Area in KSA & Type of Paper & Conclusion \\
\hline $\begin{array}{l}\text { Robert and Zamzami } \\
\text { (2014) }\end{array}$ & Riyadh & Literature Review & $\begin{array}{l}\text { Lack of nationwide, research in establishing the incidence and prevalence of strokes } \\
\text { in Saudi Arabia in recent years. Available literature points out that the crude incidence } \\
\text { rate for first-ever incidence of stroke in Saudi Arabia was 29.8/100,000/year. }\end{array}$ \\
\hline $\begin{array}{l}\text { Rajeh and Awada, } \\
2002\end{array}$ & KSA & Empirical study & $\begin{array}{l}\text { High frequency of stroke was found in young population. Reported strokes were } \\
\text { related to small artery disease, i.e. lacunar infarcts and cerebral hemorrhage. There } \\
\text { was also indication of high prevalence of diabetes mellitus as a risk factor were quite } \\
\text { distinctive. }\end{array}$ \\
\hline $\begin{array}{l}\text { Yacqub et al., 1991 } \\
\text { as cited in Robert and } \\
\text { Zamzami (2014) }\end{array}$ & Riyadh & Empirical study & $\begin{array}{l}87 \% \text { of strokes constituted Cerebral infarction. Subarachnoidd hemorrhage } \\
\text { constituted 4.5\%, Cerebral hemorrhage about 6.5\%, and venous infarction } \\
\text { constituting for 2\%. }\end{array}$ \\
\hline Ayoola et al., 2003 & Gizan & Empirical Study & $\begin{array}{l}\text { The crude incidence (estimated as 15.9 per 100, 000) in Gizan, KSA, a largely rural } \\
\text { area is lower than the reported rates in urban areas of KSA. }\end{array}$ \\
\hline Alaqeel et al., 2012 & Riyadh & Empirical study & $\begin{array}{l}\text { Of the respondents, 2862 completed the questionnaire. Out of which, 1844 (64\%) } \\
\text { were able to define stroke correctly. 1428 (49.9\%) named mass media as the source } \\
\text { of their knowledge about stroke. The study concluded that many in SA do have } \\
\text { knowledge about Stroke. }\end{array}$ \\
\hline
\end{tabular}




\begin{tabular}{|l|l|l|l|}
\hline $\begin{array}{l}\text { Salih et al., 2003 } \\
\text { Odaib and Sedairy, } \\
2014\end{array}$ & KSA & Project & $\begin{array}{l}\text { This retrospective study, spanned 10 years and 7 months, is one of the largest cohort } \\
\text { of children with stroke at one medical centre worldwide available in Saudi Arabia. } \\
\text { Among the study group of 104 Saudi children, ischemic stroke accounted for the } \\
\text { majority of cases (82\%), whereas intracranial hemorrhage was less common (18\%). }\end{array}$ \\
\hline $\begin{array}{l}\text { Ministry of health, } \\
2014\end{array}$ & KSA & Report & $\begin{array}{l}\text { A single center study in KSA showed a prevalence of stroke to be 29 per 100,000 per } \\
\text { year. The study proposed the need for larger and } \\
\text { methodologically sound studies to be conducted in order to accurately describe the } \\
\text { prevalence of stroke in KSA }\end{array}$ \\
\hline
\end{tabular}

\section{Methodology}

The methodology used in this study is counting method, cases still alive on the desired prevalence date are simply counted, since it is the most common method used in studying prevalence. The data of total stroke cases in the whole of Saudi Arabia in the year 2012-2013 is collected. The total number of population in Saudi Arabia is 27 million, including nearly 8.5 million expatriates (2010 census). The provinces of Saudi Arabia are divided as follows.

Table 2: The 13 provinces and city population and cases of stroke

\begin{tabular}{|l|l|c|c|}
\hline Province & Cities & Population & Cases \\
\hline \multirow{2}{*}{ Riyadh Province } & Riyadh & $5,328,228$ & 1632 \\
\hline & Makkah & $1,675,368$ & 380 \\
\cline { 2 - 4 } & Qunfuthah & 24,512 & 166 \\
\cline { 2 - 4 } & Jeddah & $3,456,259$ & 530 \\
\hline Madinah Province & Madinah & $1,180,770$ & 932 \\
\hline Qasim Province & Buraidah & $1,337,600$ & 868 \\
\hline Eastern Province & Hafr Al Batin & 389,993 & 160 \\
\hline \multirow{2}{*}{ Asir Province } & Abha & 366,551 & 7 \\
\hline & Al Bishah & 86,201 & 188 \\
\hline Tabuk Province & Tabuk & 569,797 & 203 \\
\hline Hail Province & Hail & 412,758 & 396 \\
\hline Northern Border Province & Ar'ar & 351,000 & 311 \\
\hline & Qurrayat & 116,162 & 63 \\
\hline \multirow{2}{*}{ Jizan Province } & Jizan & $1,497,400$ & 2150 \\
\hline & Quassim & 614,093 & 868 \\
\hline Najran Province & Najran & 555,100 & 68 \\
\hline Baha Province & Baha & 450,700 & 213 \\
\hline Jouf Province & Sakakah & 483,100 & 251 \\
\hline Eastern Province & Al Hasa & $1,063,112$ & 2345 \\
\hline
\end{tabular}

The prevalence of stroke in KSA is more difficult to estimate accurately. A prevalence of $178 / 100,000$ was reported in a community based survey from the Eastern region of KSA (Awada and Al Rajeh, 2002, Awada, 2011). Overall, the incidence and prevalence of stroke in KSA appears to be lower than the rates in the Western countries but falls within the range observed among Asian populations (Ayoola, 2003).

\section{Period Prevalence Rate of Stroke according to the data in Saudi}

By using the formula, Period prevalence $=$ Number of cases occurred in a given period/ no of people in the given population during this period $X 100$

Table 3: Period Prevalence Rate of Stroke

\begin{tabular}{|l|c|c|c|}
\hline Cities & Population in 2013 & Cases in 2013 & Prevalence \\
\hline Riyadh & $5,328,228$ & 1632 & $0.03 \%$ \\
\hline Makkah & $1,675,368$ & 380 & $0.02 \%$ \\
\hline Qunfuthah & 24,512 & 166 & $0.67 \%$ \\
\hline Jeddah & $3,456,259$ & 530 & $0.015 \%$ \\
\hline Madinah & $1,180,770$ & 932 & $0.21 \%$ \\
\hline
\end{tabular}




\begin{tabular}{|l|c|c|c|}
\hline Buraidah & $1,337,600$ & 868 & $0.064 \%$ \\
\hline Hafr Al Batin & 389,993 & 160 & $0.078 \%$ \\
\hline Abha & 366,551 & 7 & $0.001 \%$ \\
\hline Al Bishah & 86,201 & 188 & $0.035 \%$ \\
\hline Tabuk & 569,797 & 203 & $0.095 \%$ \\
\hline Hail & 412,758 & 396 & $0.095 \%$ \\
\hline Ar'ar & 351,000 & 311 & $0.088 \%$ \\
\hline Qurrayat & 116,162 & 63 & $0.05 \%$ \\
\hline Jizan & $1,497,400$ & 2150 & $0.14 \%$ \\
\hline Quassim & 614,093 & 868 & $0.14 \%$ \\
\hline Najran & 555,100 & 68 & $0.01 \%$ \\
\hline Baha & 450,700 & 213 & $0.04 \%$ \\
\hline Sakakah & 483,100 & 251 & $0.05 \%$ \\
\hline Al Hasa & $1,063,112$ & 2345 & $0.22 \%$ \\
\hline
\end{tabular}

\section{Discussion}

According to American Heart Association, 2015 "Prevalence is an estimate of how many people have a specific disease, condition or risk factor at a given point in time. These rates are applied as the population changes for several years, until a new health examination survey is done and new rates are established". It's important to realize that the prevalence rates do not change from year to year until there is a new survey. There is a dearth of nationwide data availability on stroke in the KSA.

Table 4: Crude Prevalence of stroke worldwide - Available Literature

\begin{tabular}{|c|c|c|c|}
\hline Researchers & Country & Year & Prevalence \\
\hline $\begin{array}{l}\text { Janes, Gigli, D'Anna, } \\
\text { Cancelli, Perelli, Canal, } \\
\text { Russo,Zanchettin, Valente }\end{array}$ & Italy & 2013 & $\begin{array}{l}\text { This study found that in the population, } 784 \text { stroke cases were found, and had } 81.6 \% \text { incidence } \\
\text { rate. }\end{array}$ \\
\hline $\begin{array}{l}\text { M.A. Busch } \\
\text { A. Schienkiewitz } \\
\text { E. Nowossadeck } \\
\text { A. Gößwald }\end{array}$ & Germany & 2013 & $\begin{array}{l}\text { Out of the } 914 \text { who were interviewed, it found that the lifetime prevalence of stroke in the age } \\
\text { group } 40-79 \text { years overall is } 2.9 \% \text {. }\end{array}$ \\
\hline Sun, Zou, Liu & Beijing & 2013 & Stroke cases reported were 1,285 in every 10,0000 population \\
\hline Suwanwela & Thailand & 2014 & $\begin{array}{l}\text { The most recent Thai Epidemiological Stroke Study found that the prevalence of stroke in } \\
\text { populations over the age of } 45 \text { is } 1.88 \% \text {. } \\
\text { Across all age groups in the study, men showed more prevalence than women. There was also a } \\
\text { difference reported in stroke prevalence among the five geo graphic regions of the country. The } \\
\text { highest prevalence was seen in the capital city, Bangkok (3.34\%) followed by central }(2.41 \%) \\
\text { Southern Thailand with }(2.29 \%,) \text {, northern (1.46\%), and north-eastern regions of Thailand with } \\
(1.09 \%) \text {. }\end{array}$ \\
\hline Sher, Shah and Kumar & Pakistan & 2013 & $\begin{array}{l}\text { This study showed that the rate of total stroke for those aged less than } 45 \text { years ranged from } 0.1- \\
0.3 \text { per thousand person/ years, while for those aged } 75-85 \text { years, the rate was } 10-12 \text {. This } \\
\text { study proves that stroke prevalence increases by age. }\end{array}$ \\
\hline Pandian and Sudhan & India & 2013 & $\begin{array}{l}\text { India stroke factsheet updated in } 2012 \text { shows that the estimated age-adjusted prevalence rate for } \\
\text { stroke among Indians ranges between } 84 / 100,000 \text {. When studied further there was a difference in } \\
\text { the demographic categories, which showed that } 262 / 100,000 \text { was estimated in rural areas and a } \\
\text { higher rate } 334 / 100,000 \text { and } 424 / 100,000 \text { in urban areas. }\end{array}$ \\
\hline Stroke foundation, Australia & Australia & 2013 & $\begin{array}{l}\text { In } 2012 \text {, there were over } 420,000 \text { people reported that were living with the effects of stroke. There } \\
\text { were about } 25 \% \text { more males reported with stroke }(233,171) \text { than females }(187,099) \text {. This study } \\
\text { also shows that males are more prevalent to stroke than females. }\end{array}$ \\
\hline $\begin{array}{l}\text { Tran, Mirzaeri, Anderson } \\
\text { and Leeder }\end{array}$ & Middle East & 2010 & $\begin{array}{l}\text { In this study across middle east, in Qatar the Incidence rate for all strokes ranged from } 11.7 \text { per } \\
100000 \text { that is every } 63 \text { per } 100000 \text { population. } \\
\text { Where as in Libya, the incidence rates for hemorrhagic stroke were } 2.7 \text { per } 100000 \text {. Saudi Arabia } \\
\text { showed } 1.9 \text { per } 100000 \text { stroke incidence, and } 10.4 \text { per } 100000 \text { in Iran. }\end{array}$ \\
\hline Wasay, Khatri and Kaul & SAARC & 2013 & $\begin{array}{l}\text { The estimated annual incidence of stroke in Pakistan was found to be } 250 \text { per } 100,000 \text { population. } \\
\text { It is also projected that an estimate of } 350,000 \text { new cases will increase every year. } \\
\text { Sri Lanka, with its population of about } 20 \text { million, has an estimated stroke prevalence of } 9 \text { per } \\
1,0000 \text { population. } \\
\text { Lack of empirical data from Afghanistan, Nepal, Bhutan and Maldives, makes it difficult to analyze. } \\
\text { Data from India concludes that the incidence and prevalence of stroke in this region is higher than } \\
\text { in the USA and China. }\end{array}$ \\
\hline
\end{tabular}




\begin{tabular}{|l|l|l|l|}
\hline $\begin{array}{l}\text { Centers for disease control } \\
\text { and prevention }\end{array}$ & 2013 & USA & $\begin{array}{l}\text { The prevalence of CHD/stroke among all adults aged <55 years was estimated to be } 2.8 \% . \text { This } \\
\text { includes both } \mathrm{CHD} \text { with } 2.0 \% \text { for coronary heart disease and stroke showing } 1.0 \% \text { rate. The } \\
\text { prevalence among employed adults was found to be } 1.9 \% .\end{array}$ \\
\hline
\end{tabular}

From the data, it can be understood that prior studies in Middle East were accurate indeed in establishing, that the stroke epidemic in the region is lesser than that of Asia, USA and China. This study also reveals that among the regions of Saudi, Qunfuthah, Al Hassa, Jazan and Quassim are leaning towards higher prevalence for stroke. In a similar study by Ayoola et al., 2003, collected data on patients with stroke admitted to King Fahd Central Hospital, Jizan, KSA over a 2year period from January 1997 to December 1998, and found the crude incidence (estimated as 15.9 per 100, 000) in Jizan, KSA. The researchers concluded that a national stroke registry should be strengthened to provide further information on the epidemiology of stroke in KSA.

From the study, it can be concluded that in Saudi Arabia, the prevalence of strokes is low when compared with those recorded in the Western and Asian countries. This could be due to the predominance of the younger age groups in this region. There is a need to monitor the food habits and life style of the youngsters in the country so that the stroke epidemic can be kept in check. This research brings out the fact that Saudi Arabia is still not higher in stroke epidemic and this epidemic can be controlled in the country provided more proactive screening and diagnosis can be made. Despite the food habits, money and any associated reason for stroke prediction in the GCC, Saudi Arabia can still be called healthy when it comes to stroke.

\section{References}

Ahmed Al Aqeel, Al Batool Al Ammari, Noura Alsyefi, Fawaz Al Hussain and Yousef Mohammad (2012) Stroke Awareness in the Saudi Arabia Community: Prompt Public Health Measures Must Be Implement available at URL http://www.neurology.org/cgi/content/ meeting_abstract/78/1_MeetingAbstracts/P07.010

Akala FA, El-Saharty S. Public-health challenges in the Middle East and North Africa. Lancet. 2006;367(9515):961-4.

Akbar, D., Mushtaq, M and Sultan Quaboos (2001) Clinical profile of stroke at King Abdulaziz University hospital, Journal for scienfitic research, 1, 35- 38

Ali N. Al-Odaib, and Sultan T. Al-Sedairy, An overview of the Prince Salman Center for Disability Research scientific outcomes, Saudi Med J. 2014; 35(Suppl 1): S75-S90 available at URL http://www.ncbi.nlm.nih.gov/pmc/articles/PMC4362095/

Al-Jishi AA, Mohan PK. Profile of stroke in Bahrain. Neurosiences 2000;5:30-4.

Al Khathaami AM, Algahtani H, Alwabel A, Alosherey N, Kojan S, Aljumah M. The status of acute stroke care in Saudi Arabia: an urgent call for action! Int J Stroke. 2011; 6(1):75-6.

Al Rajeh S, Awada A, Niazi G, Larbi E. Stroke in a Saudi Arabian National Guard community. Analysis of 500 consecutive cases from a population-based hospital. Stroke. 1993;24(11):1635-9. Available at http://stroke.ahajournals.org/content/24/11/1635.full.pdf

Al Rajeh S, Awada A. Stroke in Saudi Arabia. Cerebrovasc Dis. 2002;13(1):3-8.

Alzharani, M., Madya, P. Ahmad, A and Aljaaidi, K.'An Empirical Investigation of Factors Associated with Firm Performance: Evidence from Kingdom of Saudi Arabia', International Conference on E- business Management and Economics Analysis, 2011, Vol. 25, No. 4, Pp.30- 36 .

American Heart Association (2015) Available at URL http://www.heart.org/HEARTORG/General/Heart-and-Stroke-AssociationStatistics_UCM_319064_SubHomePage.jsp

Awada A. Primary and secondary prevention of ischemic stroke. J Med Liban. 2011; 59(4):213-9.

Awada A and Rajeh S. The Saudi Stroke Data Bank. Analysis of the first 1000 cases. Acta Neurol Scand. 1999; 100(4):265-9.

Ayoola, A. E., Subodh S. Banzal, Abdulhadi K. Elamin, Mohamed O. Gadour, Eltayeb W. Elsammani, Mohamed H. Al-Hazmi, (2003) Profile of stroke in Gizan,Kingdom of Saudi Arabia, Neurosciences, Vol. 8 (4): 229-232.

Busch, M.A, Schienkiewitz, A., Nowossadeck, E., Gößwald, A. (2013) Prevalence of stroke in adults aged 40 to 79 years in Germany: results of the German Health Interview and Examination Survey for Adults (DEGS1)]. Bundesgesundheitsblatt Gesundheitsforschung Gesundheitsschutz. 2013, May;56(5-6):656-60. doi: 10.1007/s00103-012-1659-0. German. Available at URL http://edoc.rki.de/oa/articles/rezpW553Zk0zA/PDF/27Sbld1R4s96.pdf

Centers for disease control and prevention (2013) available at URL www.cdc.gov/stroke, http://www.nature.com/

Haixin Sun, Xinying Zou, and Liping Liu (2013) Epidemiological Factors of Stroke: A Survey of the Current Status in China, J Stroke. May 2013; 15(2): 109-114.

Janes F, Gigli GL, D'Anna L, Cancelli I, Perelli A, Canal G, Russo V, Zanchettin B, Valente M. Int J Stroke. 2013 Stroke incidence and 30-day and six-month case fatality rates in Udine, Italy: a population-based prospective study. Oct;8 Suppl A100:100-5. doi: 10.1111/ijs.12000. Epub 2013 Mar 21.

Jeffrey Algazy,; Steven Gipstein,; Farhad Riahi, and Katherine Tryon, , 2009, Why governments must lead the fight against obesity, URL available at http://www.animateeu.com/public/news/active/375/McKinsey\%20quarterly_Why\%20governments\%20must\%20lead \%20the\%20fight\%20against\%20obesity\%20plus\%20posts.pdf

Kamran S, Bener AB, Deleu D, Khoja W, Jumma M, Al Shubali A, et al. The level of awareness of stroke risk factors and symptoms in 
the Gulf Cooperation Council countries: Gulf Cooperation Council stroke awareness study. Neuroepidemiology. 2007;29(34):235-42.

Ministry of Health (2014) available at URL http://www.moh.gov.sa/endepts/TCP/Documents/5.\%20Stroke\%20-\%20Use\%20of\%20 Thrombolytic\%20Therapy\%20in\%20Acute\%20Stroke.pdfl

Mourshed M, Hediger V, Lambert T. Gulf Cooperation Council Health Care: Challenges and Opportunities [internet]. 2008. Available from: http://www.weforum.org/pdf/Global_Competitiveness_Reports/Reports/chapters/2_1.pdf

Nijasri C. Suwanwela (2014) Stroke Epidemiology in Thailand, Stroke. Jan 2014; 16(1): 1-7.

Pandian, J. D. and P. Sudhan (2013). "Stroke epidemiology and stroke care services in India." J Stroke 15(3): 128- 134, Available at URL http://www.ncbi.nlm.nih.gov/pmc/articles/PMC3859004/

Qari FA. Profile of stroke in a teaching university hospital in the western region. Saudi Med J. 2000 Nov;21(11):1030-3.

Robert,A. A., Marwan Mohamed Zamzami. Stroke in Saudi Arabia: a review of the recent literature. The Pan African Medical Journal. 2014:17:14

Salih MA, Abdel Gader AG, Al Jarallah AA, (2006). Perinatal stroke in Saudi children. Clinical features and risk factors. Saudi Med J; 27suppl 1: S35-S40.

Sinaa A. AL Aqeel, , Mohammed Al-Sultan The use of pharmacoeconomic evidence to support formulary decision making in Saudi Arabia: Methodological recommendations. Saudi Pharmaceutical Journal, Volume 20, Issue 3, July 2012, Pages 187-194

Sher K, Shah S, Kumar S. (2013) Etiologic patterns of ischaemic stroke in young adults. J Coll Physicians Surg Pak. Jul;23(7):472-5. doi: 07.2013/JCPSP.472475.

Stroke foundation, Australia (2013), available at URL, strokefoundation.com.au

Suwanwela, N.C. Stroke Epidemiology in Thailand, J Stroke. 2014 Jan; 16(1): 1-7.

Tran J, The epidemiology of stroke in the Middle East and North Africa, J Neurol Sci (2010), doi:10.1016/j.jns.2010.05.016

Tran J, Mirzaei M, Anderson L, Leeder SR. The epidemiology of stroke in the Middle East and North Africa. J Neurol Sci. 2010;295(12):38-40

Wasay M, Khatri IA, Kaul S (2014) Stroke in South Asian countries. Nat Rev Neurol. 2014 Mar;10(3):135-43. doi: 10.1038/nrneurol. 2014.13. Epub 2014 Feb 11.

Yaqub BA, Shamena AR, Kolawole TM, Patel PJ. Cerebrovascular disease in Saudi Arabia. Stroke. 1991; 22(9):1173-6. 